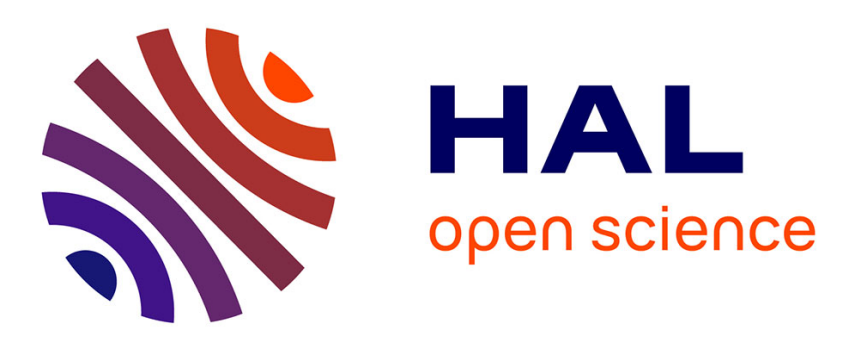

\title{
Modeling zirconia sintering trajectory for obtaining translucent submicronic ceramics for dental implant applications
}

Charles Manière, Geuntak Lee, Joanna Mckittrick, Shirley Chan, Eugene A. Olevsky

\section{To cite this version:}

Charles Manière, Geuntak Lee, Joanna Mckittrick, Shirley Chan, Eugene A. Olevsky. Modeling zirconia sintering trajectory for obtaining translucent submicronic ceramics for dental implant applications. Acta Materialia, 2020, 188, pp.101-107. 10.1016/j.actamat.2020.01.061 . hal-02616736

HAL Id: hal-02616736

https://hal-normandie-univ.archives-ouvertes.fr/hal-02616736

Submitted on 20 Nov 2020

HAL is a multi-disciplinary open access archive for the deposit and dissemination of scientific research documents, whether they are published or not. The documents may come from teaching and research institutions in France or abroad, or from public or private research centers.
L'archive ouverte pluridisciplinaire HAL, est destinée au dépôt et à la diffusion de documents scientifiques de niveau recherche, publiés ou non, émanant des établissements d'enseignement et de recherche français ou étrangers, des laboratoires publics ou privés. 


\title{
Modeling zirconia sintering trajectory for obtaining translucent submicronic ceramics for dental implant applications
}

Charles Manière $^{\mathrm{a} *}$, Geuntak Lee ${ }^{\mathrm{a}, \mathrm{b}}$, Joanna McKittrick $^{\mathrm{b}}$, Shirley Chan ${ }^{\mathrm{a}}$, Eugene A. Olevsky ${ }^{\mathrm{a}, \mathrm{c}}$

(a) Powder Technology Laboratory, San Diego State University, San Diego, USA

(b) Mechanical and Aerospace Engineering, University of California, San Diego, La Jolla, USA

(c) NanoEngineering, University of California, San Diego, La Jolla, USA

\section{Keywords}

Modeling, Sintering Trajectory, Translucent, Dental Implant, Two Step Sintering, Zirconia

\begin{abstract}
Attaining high densification without grain growth is one of the main objectives of the sintering optimization in ceramic materials. For dental implant applications, achieving this objective has a decisive impact on the mechanical resistance, the duration and the translucency of the implant. To improve these sintering outcomes a long experimental explorative study is generally required. In this work, we developed a combined experimental/modeling approach allowing a rapid identification of the optimal sintering conditions. The determination of the model densification and grain growth kinetic constitutive parameters has been done experimentally. We found that the sintering/grain growth kinetics have a detrimental acceleration above a critical temperature level. The pressure-less sintering model able to predict the sintering stress, powder densification and grain growth has been used for the determination of the optimal sintering trajectory. We utilized the two step sintering method to approach the critical temperature without an undesirable grain growth. We obtained translucent sintered specimens with a very limited grain growth.
\end{abstract}

\footnotetext{
* Corresponding author: CM: Powder Technology Laboratory; College of Engineering; San Diego State University; 5500 Campanile Drive; San Diego, CA 92182-1323

Ph.: +1(619)-594-6329; Fax: +1(619)-594-3599 ; E-mail: charles.maniere@ensicaen.fr
} 


\section{Nomenclature}

$\theta$ Porosity

$\dot{\theta}$ Porosity rate $\left(\mathrm{s}^{-1}\right)$

$\underline{\sigma}$ Stress tensor $\left(\mathrm{N} . \mathrm{m}^{-2}\right)$

$\underline{\dot{\varepsilon}}$ Strain rate tensor $\left(\mathrm{s}^{-1}\right)$

$\dot{e}$ The trace of the strain rate tensor $\left(\mathrm{s}^{-1}\right)$

$\dot{\varepsilon}_{r}$ Radial component of isotropic strain rate tensor $\left(\mathrm{s}^{-1}\right)$

$\varphi$ Shear modulus

$\psi$ Bulk modulus

$P l$ Sintering stress $(\mathrm{Pa})$

il Identity tensor

$\alpha$ Surface energy (J.m $\left.{ }^{-2}\right)$

$r$ Grain radius (m)

$\eta$ Material viscosity (Pa.s)

$\eta_{0}$ Viscosity pre-exponential factor (Pa.s)

$Q$ Viscosity activation energy $\left(\mathrm{J} \cdot \mathrm{mol}^{-1}\right)$

$R$ Gas constant $8.314\left(\mathrm{~J} \cdot \mathrm{mol}^{-1} \cdot \mathrm{K}^{-1}\right)$

$T$ Temperature (K)

$\dot{G}$ Grain growth rate $\left(\mathrm{m} . \mathrm{s}^{-1}\right)$

$G$ Grain size (m)

$G_{0}$ Initial grain size (m)

$p$ Grain growth exponent

$K$ Grain growth factor $\left(\mathrm{m}^{1+p} \cdot \mathrm{s}^{-1}\right)$

$k_{0}$ Grain growth pre-exponential factor $\left(\mathrm{m}^{1+p} \cdot \mathrm{s}^{-1}\right)$

$Q_{G}$ Grain growth activation energy $\left(\mathrm{J} \cdot \mathrm{mol}^{-1}\right)$

$m$ the viscosity grain size exponent

$C$ a constant

$w$ the sintering equation grain size exponent

$D$ the diffusion coefficient

$k$ the Boltzmann constant (1.38064852E-23 J.K $\left.{ }^{-1}\right)$ 


\section{Introduction}

Attaining a final high relative density and a minimum of grain growth are required sintering outcomes for obtaining translucent zirconia dental implants with high mechanical strength [15]. Pressures-less sintering modeling is an efficient way to optimize the grain growth/densification sintering trajectory for different thermal cycles. It requires a careful identification of the densification/grain growth during the final stage of sintering. Grain growth is known to slow down the sintering kinetics by reducing the sintering stress and longer diffusion distances in the grains [6-8]. The traditional sintering models consider a grain size and porosity dependence of the effective sintering stress [9]. On the other hand, grain growth induces longer diffusion distances within the grain lattice and at the grain boundaries [6]. This phenomenon is particularly known for diffusional creep, where larger grains are associated with slower creep rates (at the same temperature) due to longer grain boundaries or lattice diffusion distances. The grain growth kinetics is known to be affected by porosity (porosity pinning), which results in the different grain growth mechanisms for high and low porosity stages of sintering [6,7]. In the generalized form of the continuum theory of sintering, it is usually assumed that the grain growth modifies the sintering stress and the material's equivalent deformation behavior (viscosity for linear viscous constitutive behavior, and the creep properties for nonlinear viscous constitutive behavior) [10]. The prediction of the densification/grain growth kinetics and their interaction during the sintering process is the key for understanding the sintering final stage phenomena $[8,11]$. For spark plasma sintering [12], the information on the densification/grain growth interaction can be used to optimize the densification curve at the end of the cycle [13].

In this work, we investigate the possibility to predict by an analytic sintering/grain growth model the sintering trajectory of a zirconia powder dental implant. In this regard, the implant should simulate the translucent aspect of natural teeth and have high mechanical properties to 
resist the chewing stress and to extend the implant duration [5]. Minimal porosity and grain sizes are required to optimize these characteristics. First, we will explore the implant material's experimental sintering response (in terms of porosity and grain size) under different sintering temperatures and holding cycles. Based on this, the sintering/grain growth model will be calibrated to follow the experimental data points and the explored sintering trajectory. When the model renders a satisfactory response, it will be employed to virtually adjust different sintering cycles using long holding times (a long exploration time would be needed if the material were tested experimentally). We will, in particular, explore the two step sintering method to optimize the sintering trajectory [14]. Then the optimized cycle will be tested experimentally for verification.

\section{Theory and calculations}

The sintering model employed is based on the continuum theory of sintering [9]. This approach allows an easy identification of the sintering parameters using the analytic constitutive equations and provides the possibility to use these parameters in finite element simulations. The constitutive equation describing the linear viscous densification behavior of a compressible medium taking into account the sintering stress $P_{l}$ is defined as:

$\underline{\sigma}=2 \eta\left(\varphi \underline{\dot{\varepsilon}}+\left(\psi-\frac{1}{3} \varphi\right) \dot{e} \mathbb{1}\right)+P_{l} \stackrel{\mathbb{1}}{1}$

with the invariant (volumic shrinkage rate):

$\dot{e}=\dot{\varepsilon}_{x}+\dot{\varepsilon}_{y}+\dot{\varepsilon}_{z}$

and the Skorohod's sintering stress expression [15] for the capillarity forces developed at the particles contacts:

$P l=\frac{3 \alpha}{r}(1-\theta)^{2}$ 
Equation (1) gives the sintering deformation behavior of a linear viscous medium. The porosity evolution rate is linked to the rate of volume change through the mass conservation equation:

$\frac{\dot{\theta}}{1-\theta}=\dot{\varepsilon}_{x}+\dot{\varepsilon}_{y}+\dot{\varepsilon}_{z}$

For pressure-less isotropic sintering, the stress and strain rate tensors can be reduced to:

$\underline{\sigma} \equiv\left(\begin{array}{ccc}0 & 0 & 0 \\ 0 & 0 & 0 \\ 0 & 0 & 0\end{array}\right) \quad ; \quad \underline{\dot{\varepsilon}} \equiv\left(\begin{array}{ccc}\dot{\varepsilon}_{r} & 0 & 0 \\ 0 & \dot{\varepsilon}_{r} & 0 \\ 0 & 0 & \dot{\varepsilon}_{r}\end{array}\right)$ isotropic $\dot{e}=3 \dot{\varepsilon}_{r}$

Equation (1) becomes:

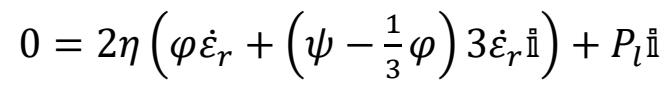

We obtain the reduced expression:

$-P_{l}=2 \eta 3 \dot{\varepsilon}_{r} \psi$

Using the mass conversation (4), we obtain [9]:

$\psi=\frac{-P_{l}(1-\theta)}{2 \eta \dot{\theta}}$

and then, the analytic equation describing the rate of porosity elimination [9];

$\dot{\theta}=\frac{-P_{l}(1-\theta)}{2 \eta \psi}$

Equation (9), can be used to model the sintering densification. However, at the sintering final stage, the grain growth will influence the sintering stress (3) and the viscosity. The grain growth kinetics is usually modeled by the following equation $[6,7,16]$ :

$\dot{G}=\frac{K}{G^{p}}=\frac{k_{0}}{G^{p}} \exp \left(\frac{-Q_{G}}{R T}\right)$

The viscosity temperature and grain size dependence can be defined by the expression $[8,11,13,17]:$ 
$2 \eta=\left(\frac{G}{G_{0}}\right)^{m} \eta_{0} T \exp \left(\frac{Q}{R T}\right)$

Substituting the expression of the sintering stress (3) and the viscosity (11) in Eq. (9), we obtain the expression of the rate of porosity evolution which takes into account the actual grain size $(G)$.

$\dot{\theta}=\frac{-6 \alpha(1-\theta)^{3}}{G^{m+1} \frac{\eta_{0}}{G_{0}^{m}} T \exp \left(\frac{Q}{R T}\right) \psi}$

This equation can be compared to the theoretical equations of solid-state sintering which have the general form $[6,18-20]$ :

$\dot{\theta}=\frac{-C f(\theta) \alpha D}{G^{w} k T}$

In this equation, $C$ is a constant, $f(\theta)$ a function of the porosity, and $D$ the diffusion coefficient ( $D_{v}$ for volume diffusion and $\delta_{g b} D_{g b}$ for grain boundary diffusion) which has an Arrhenius form. From Coble [21] sintering models and in accordance with Herring's scaling law [22], the grain size exponent $w$ in (13) has a value of 4 for grain boundary diffusion and 3 for volume diffusion [6]. Comparing (12) and (13), we can see that all the constants $\left(G_{0}, m, k\right.$, 6) of Eq. (12) are included in $C$ constant, the exponential term is included in the diffusion coefficient, $f(\theta)$ gather all the porosity terms in Eq. (12) including the bulk modulus $\psi$ and the sintering stress porosity function, and we have, $w=m+1$.

In order to determine the viscosity parameters and the surface energy, equation (12) was written in the following form, enabling the constitutive parameters' identification by a linear regression:

$Y=\ln \left(\frac{-3(1-\theta)^{3}}{r T \dot{\theta} \psi}\right)=\ln \left(\frac{\eta_{0}}{\alpha}\right)+\frac{Q}{R T}$ 


\section{Experiment and method}

This study employs Tosoh Zpex Smile zirconia powder specimens prepared by 200 MPa Cold Isostatic Pressing (CIP American isostatic pressing). In order to identify the sintering densification behavior using Eq. (14), a dilatometry test was performed (Unitherm model 1161 , Anter Corporation) at $5 \mathrm{~K} / \mathrm{min}$ up to $1650^{\circ} \mathrm{C}$. For the determination of the grain growth kinetics, we conducted different sintering tests with a $5 \mathrm{~K} / \mathrm{min}$ heating ramp and two hours of holding at different temperatures. To determine the grain growth rate exponent $p$, we conducted interrupted dwell experiments for a temperature level at the onset of grain growth in the sintering trajectory $\left(1550{ }^{\circ} \mathrm{C}\right.$ see later). The mean grain diameter was calculated through the scanning electron microscopy (SEM FEI Quanta 450, USA) of polished and thermally etched samples; the linear intercept method using Mendelson's stereological factor was used [23]. After obtaining the average grain size and the relative density of all samples, the grain growth exponent $p$ and $K$ factor were determined for the interrupted sintering tests at $1550{ }^{\circ} \mathrm{C}$. Then, the sintering data obtained using equation (14)-based regression of the dilatometry test was employed to simulate all the sintering experiments. The model of sintering during the final stage was particularly adjusted using the grain growth relationship to determine the grain growth activation energy $Q_{G}$. After a reasonable prediction of all the sintering tests at different temperatures, the densification and grain growth data were used to determine an optimized sintering cycle.

\section{Results and discussions}

\subsection{Sintering tests}

The sintering process design and obtained specimens' average grain sizes and relative density are reported in figure 1 . The experimental process design consists of a sintering cycle with a 
heating ramp of $5 \mathrm{~K} / \mathrm{min}$ and a 2 hours holding time under temperatures between 1200 and $1700{ }^{\circ} \mathrm{C}$ (see figure 1a). The experiments at $1550{ }^{\circ} \mathrm{C}$ were carried out at different holding times to reveal the isothermal grain growth behavior (see figure 1b). For the different tests conducted with 2 hours of holding time, the average relative densities and grain sizes are reported in figure 1(c and d). It is interesting to note in figure 1d two different grain growth behaviors: a slow grain growth behavior for temperatures below $1550{ }^{\circ} \mathrm{C}$ and a behavior which has faster grain growth kinetics for higher temperatures. A possible explanation of this change of the grain growth behavior could be a slower grain growth kinetics due to the intergranular porosity pinning which slows down the grain boundary mobility $[6,7]$. The grain growth curves (figure 1d) and the densification data (figure 1c) show that this transition cannot by easily related to the specimen's overall densification, but it seems more influenced by the temperature which accelerates the grain boundaries' mobility. This slower grain growth zone is of high importance for our study which is essentially focused on the slow kinetics zone (blue arrow in figure 1d with low grain boundary mobility) to eliminate the porosity with a minimum of the grain growth. It is important to avoid the formation of an intragranular porosity which is known to be very difficult to eliminate $[6,7]$. 

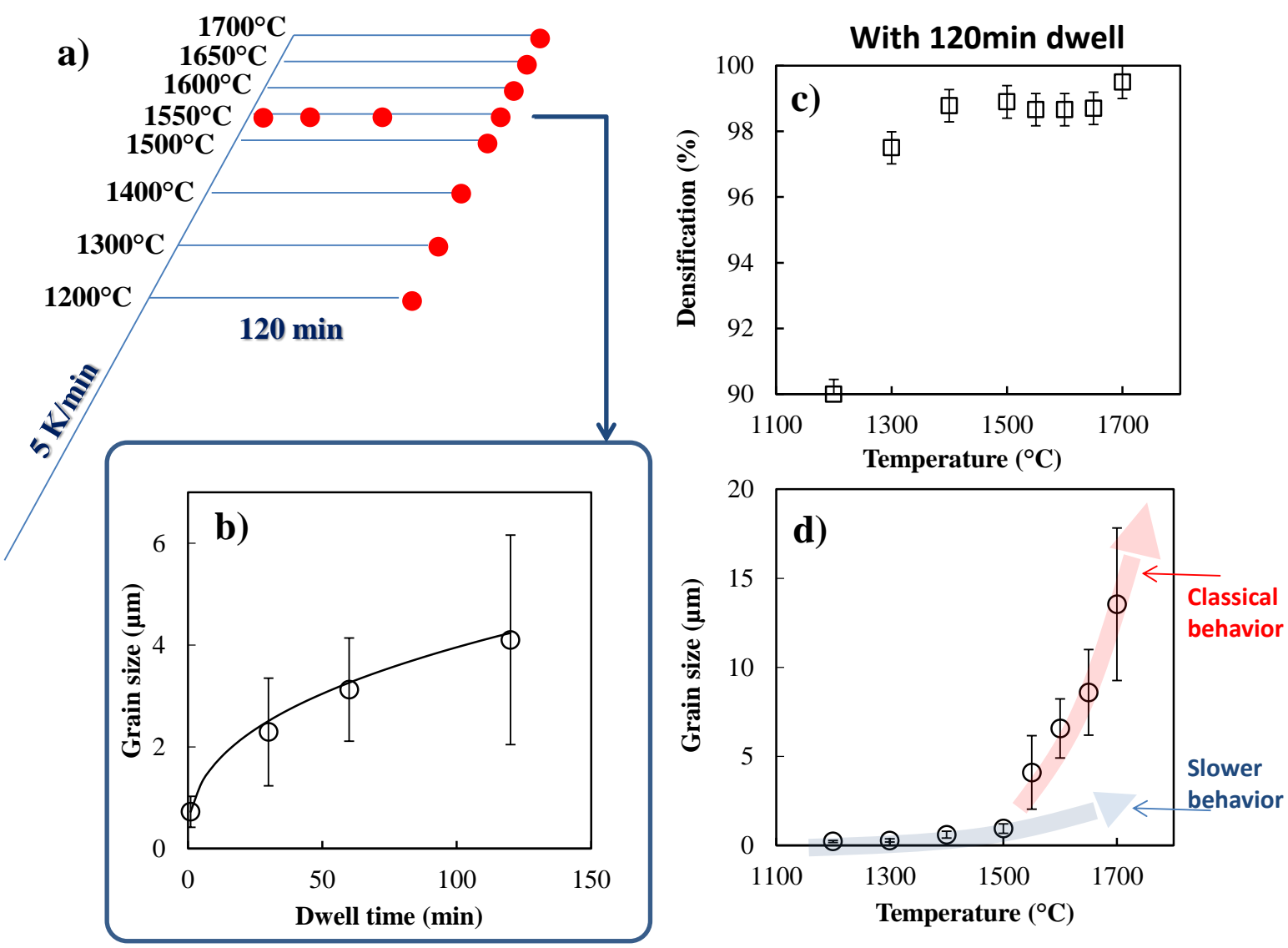

Figure 1 Experimental exploration of Zpex Smile zirconia pressure-less sintering, a) sintering cycles, b) grain size evolution in $1550^{\circ} \mathrm{C}$ tests, $c$ ) densification of the specimens obtained with 120 min dwell, $d$ ) average grain size of 120 min dwell specimens.

\subsection{Identification of the modeling parameters}

\subsubsection{Sintering dilatometry}

An important step of this study is to determine the densification parameters of the employed powder during the $5 \mathrm{~K} / \mathrm{min}$ heating ramp. Our entire study is focused on this heating ramp to avoid extensive constitutive parameter identification tests. A sintering dilatometry is performed for this heating ramp. The densification data $(\dot{\theta}, \theta)$ are extracted to plot based on Eq. (14) the regression graph of figure $2 \mathrm{a}$ which gives the ratio $\eta_{0} / \alpha$ of $0.0085 \mathrm{~Pa} \cdot \mathrm{m}^{2} . \mathrm{s} . \mathrm{J}^{-1} . \mathrm{K}^{-1}$ and the densification activation energy $Q$ of $295 \mathrm{~kJ} \cdot \mathrm{mol}^{-1}$. The sintering constitutive parameter identification zone is reported in figure $1 \mathrm{~b}$ and represents an area where the grain growth is 
not active. This graph reports also the model of the dilatometry test with and without grain growth. This shows the influence of the grain growth at the end of the sintering cycle where the sintering rate is decreased.

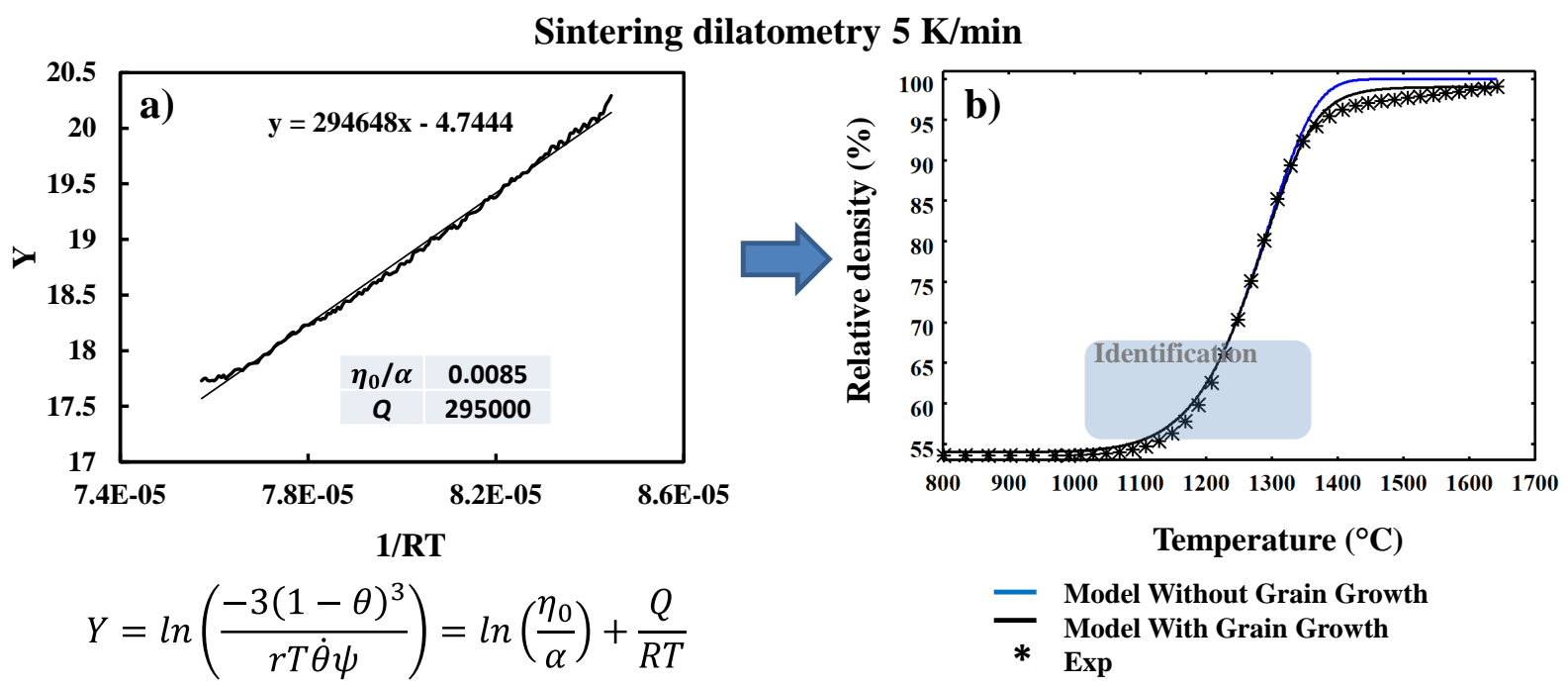

Figure 2 Identification of the densification behavior based on $5 \mathrm{~K} / \mathrm{min}$ sintering dilatometry (a) and experimental densification data modeled with and without grain growth (b).

\subsubsection{Grain growth at $1550^{\circ} \mathrm{C}$}

To estimate the grain growth exponent $p$, the interrupted dwell tests were carried out under $1550{ }^{\circ} \mathrm{C}$ (during the grain growth behavior transition). Using equation (10) in a logarithm form and the data in figure $1 \mathrm{~b}$, it is possible to determine the grain growth exponent $p$ and the pre-exponential factor $K$ for $1550{ }^{\circ} \mathrm{C}$ by a regression approach reported in figure 3 . We obtained the value $p$ of 1.63 and a $K$ value of $3.74 \mathrm{E}-19 \mathrm{~m}^{1+p} . \mathrm{s}^{-1}$. We use these data to calibrate $k_{0}$ and $Q_{G}$ corresponding to the generalized grain growth behavior (the data of figure 1) and the analytical model which utilizes equations $(4,10,12)$ and assumes the dominant grain boundary diffusion densification mechanism [6,20]. 


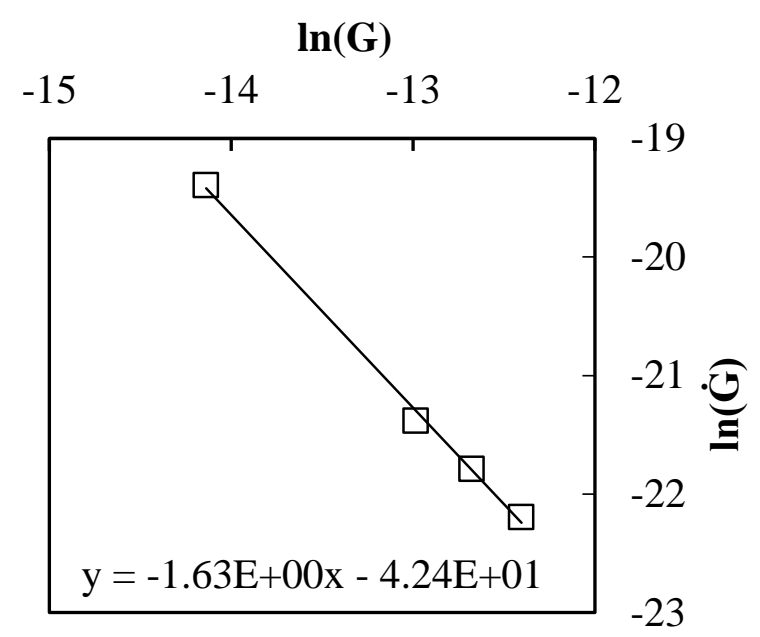

Figure 3 Grain growth parameters identification at $1550^{\circ} \mathrm{C}$.

\subsubsection{Grain growth below $1550^{\circ} \mathrm{C}$}

Using the densification parameters of figure 2, the sintering/grain growth analytical model was employed to calibrate the grain growth behavior $\left(k_{0}\right.$ and $\left.Q_{G}\right)$ with the grain size data below $1550{ }^{\circ} \mathrm{C}$. The results are reported in figure 4 . One can see that the $1200{ }^{\circ} \mathrm{C}$ experiment has almost no grain growth and an incomplete densification. The grain growth kinetics is slow until $1300{ }^{\circ} \mathrm{C}$ where it becomes active. In the temperature zone of figure 4 we obtained the grain growth parameters of $k_{0}=1.5 \mathrm{E}-4 \mathrm{~m}^{1+p} \cdot \mathrm{s}^{-1}$ and $Q_{G}=600 \mathrm{~kJ} \cdot \mathrm{mol}^{-1}$. These values are of high importance for the sintering optimization study because they represent the grain growth kinetics in the transition from high to low porosities. 

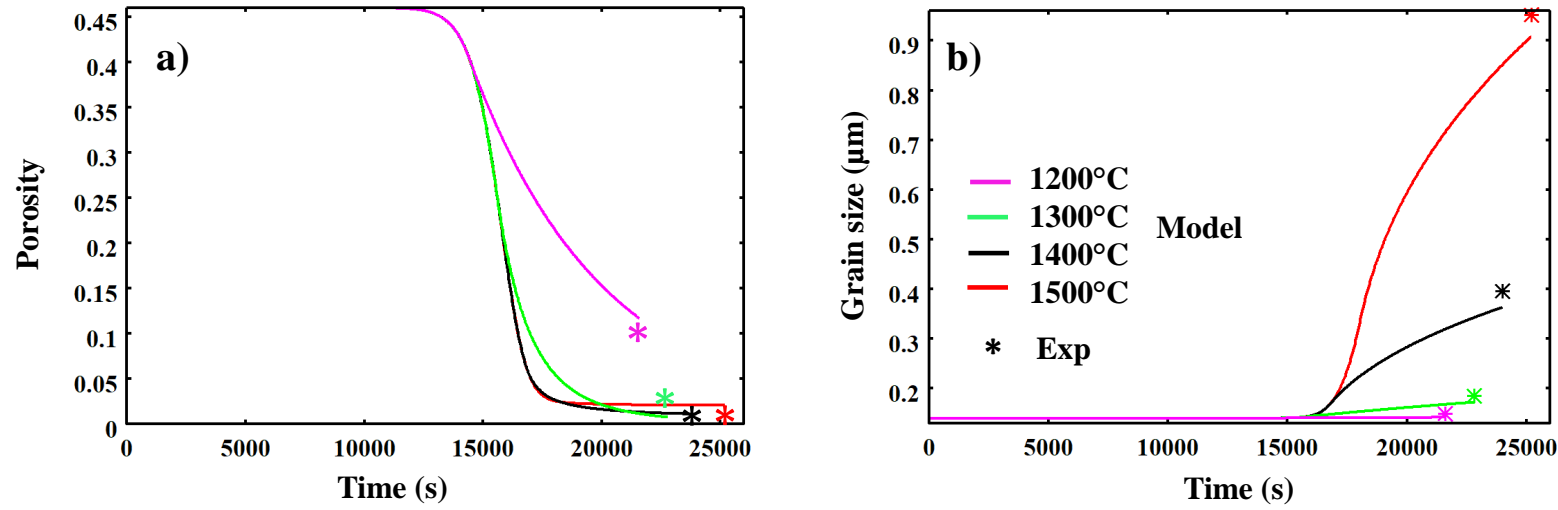

Figure 4 Identification of the grain growth kinetics below $1550{ }^{\circ} \mathrm{C}$, a) modeled porosity evolution, b) modeled grain size evolution.

\subsubsection{Grain growth above $1550^{\circ} \mathrm{C}$}

In order to predict the grain growth for higher temperatures, the grain growth model has been also calibrated for temperatures above $1550{ }^{\circ} \mathrm{C}$. The results are reported in figure 5 . Because the temperatures are within a high range, the main part of the densification is conducted during the $5 \mathrm{~K} / \mathrm{min}$ heating ramp and the grain growth dominates the high temperature densification. In consequence, the densification occurs up to $97.5 \%$ of the relative density regardless of the temperature cycle (see figure 1a). This phenomenon is observed experimentally (figure 1c) where the final relative density seems to stabilize close to $98.6 \%$ for temperatures above $1400^{\circ} \mathrm{C}$. We obtained the following grain growth values: $k_{0}=0.058 \mathrm{~m}^{1+p} \cdot \mathrm{s}^{-1}$ and $Q_{G}=600 \mathrm{~kJ} \cdot \mathrm{mol}^{-1}$. 

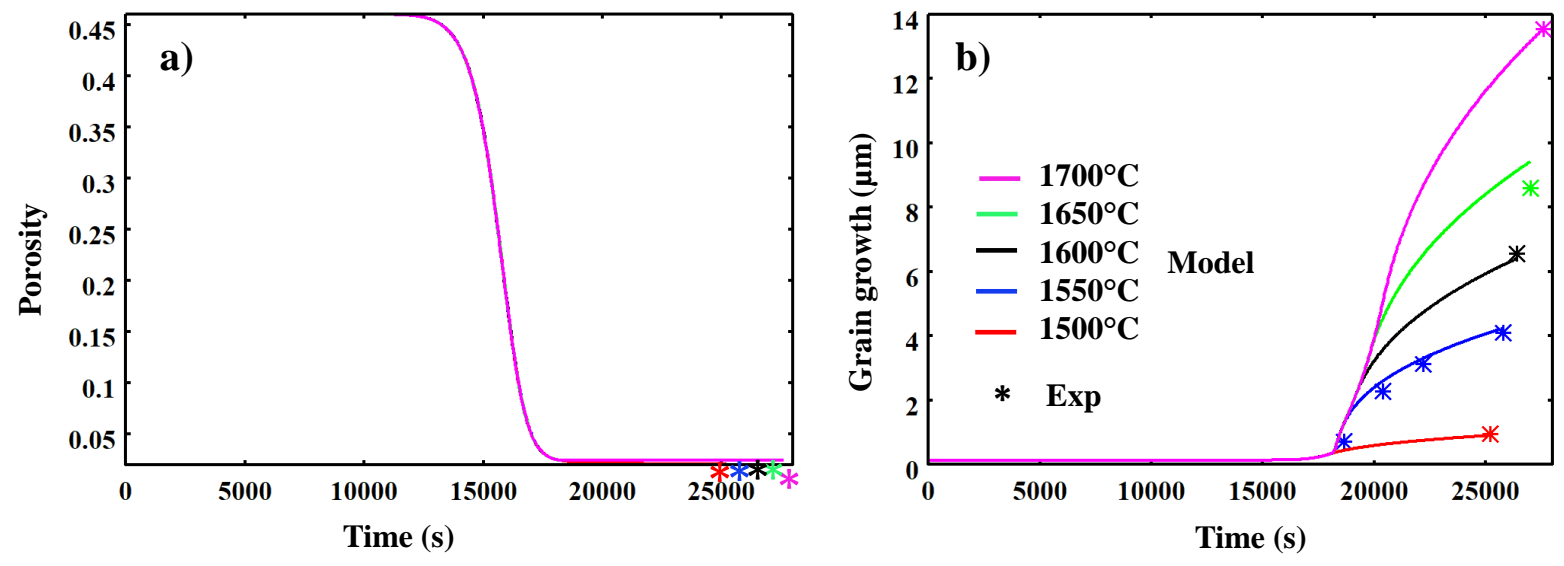

Figure 5 Identification of the grain growth kinetics above $1500^{\circ} \mathrm{C}$, a) modeled porosity evolution, b) modeled grain size evolution.

\subsubsection{Thermal transition of the grain growth behavior}

In the generalized grain growth model we chose to model the transition from the low to high temperature behaviors via a sigmoidal function (15) which gives 0 for low temperatures and 1 for high temperatures.

$\mathrm{f} 0=\frac{1}{1+\exp (-0.1(T-T c r))}$

Based on the results figure $1 \mathrm{~d}$, the critical temperature $T c r$ was chosen to be $1793 \mathrm{~K}$. This function is reported in figure 6. At this stage, the sintering/grain growth model is fully identified, and the sintering optimization can be conducted using the determined constitutive parameters. 


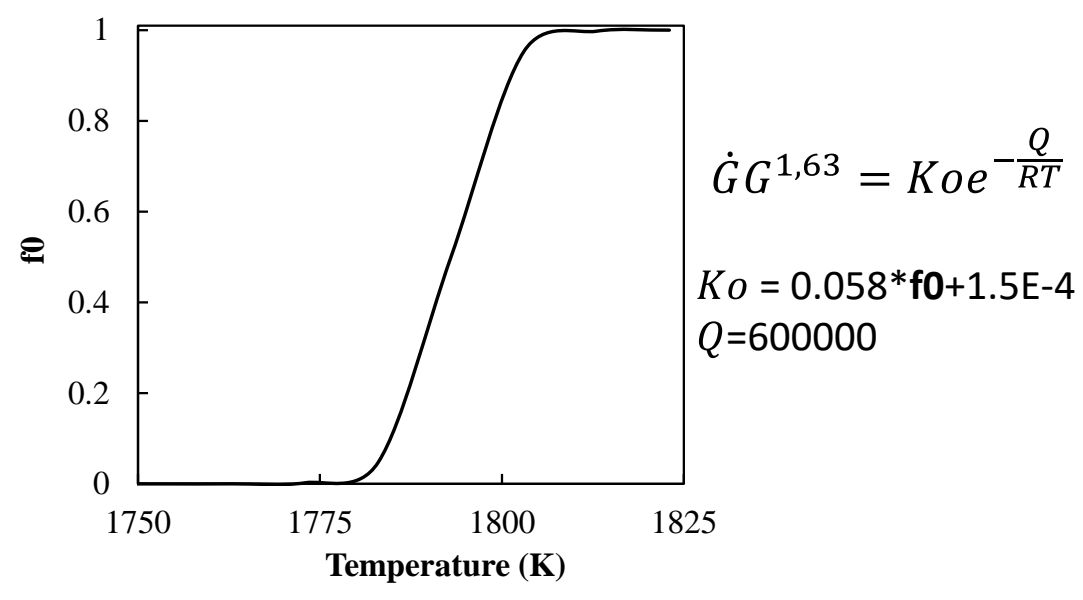

Figure 6 Sigmoidal function used to model the grain growth behavior transition between 1500 and $1550{ }^{\circ} \mathrm{C}$.

\subsection{Modeling of optimized sintering trajectories}

The modeling optimization study is conducted using the two step sintering method. This method consists of an initial heating to a maximum temperature followed by a temperature decrease down to a long holding temperature which is lower than the maximum temperature attained at the end of the initial heating ramp. This approach has shown an interesting potential for the improvement of the sintering trajectory without the help of an externally applied pressure [14]. In the present study, (see figure 7a) a $5 \mathrm{~K} / \mathrm{min}$ heating ramp is applied to the highest temperature under which the grain growth is not highly active $\left(1400{ }^{\circ} \mathrm{C}\right)$. After reaching this temperature, a $5 \mathrm{~K} / \mathrm{min}$ decrease is applied to reach different lower temperatures held during 10 hours to ensure a slow but active densification. The obtained porosity and grain size evolution curves are reported in figure $7 \mathrm{a}$ and figure $7 \mathrm{~b}$, respectively. From the modeled sintering trajectory reported in figure $7 \mathrm{~d}$, one can see that the optimal sintering cycle having a maximal densification for a limited grain growth corresponds to the cycle with a holding temperature of $1300{ }^{\circ} \mathrm{C}$. One can clearly see that the regular one-step sintering cycle (in red) causes an excessive grain growth which prevents attaining high densification. 

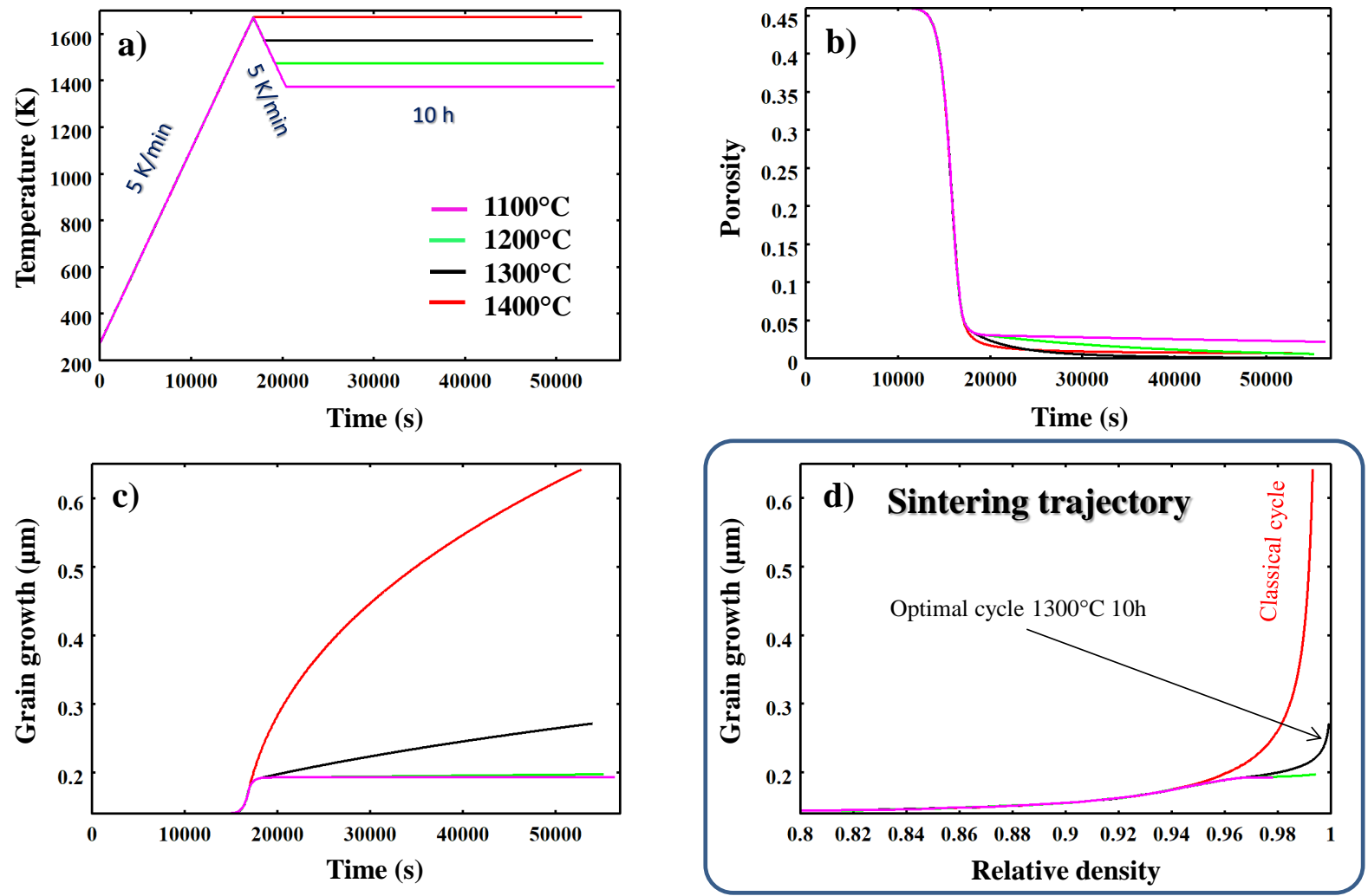

Figure 7 Modeled sintering trajectories for the optimization of the sintering of the zirconia samples through the two step sintering approach, a) Temperature cycles, b) modeled porosity evolution, c) modeled grain size evolution, d) modeled sintering trajectories.

\subsection{Experimental verification}

The obtained by modeling optimal sintering cycle at $1300{ }^{\circ} \mathrm{C}$ has been tested experimentally. The respective microstructure is reported in figure 8 . The average grain size is $285 \mathrm{~nm}$, which is close to the $272 \mathrm{~nm}$ obtained in the modeling approach. The presence of localized porosity is observed (blue arrow) while the model predicted a quasi-full densification. However, this experimentally observed porosity seems to be very localized and can be caused by compaction defects or impurities which can generate a similar porosity not homogeneously distributed around the grains (and not predicted by the model). 
$25000 X$

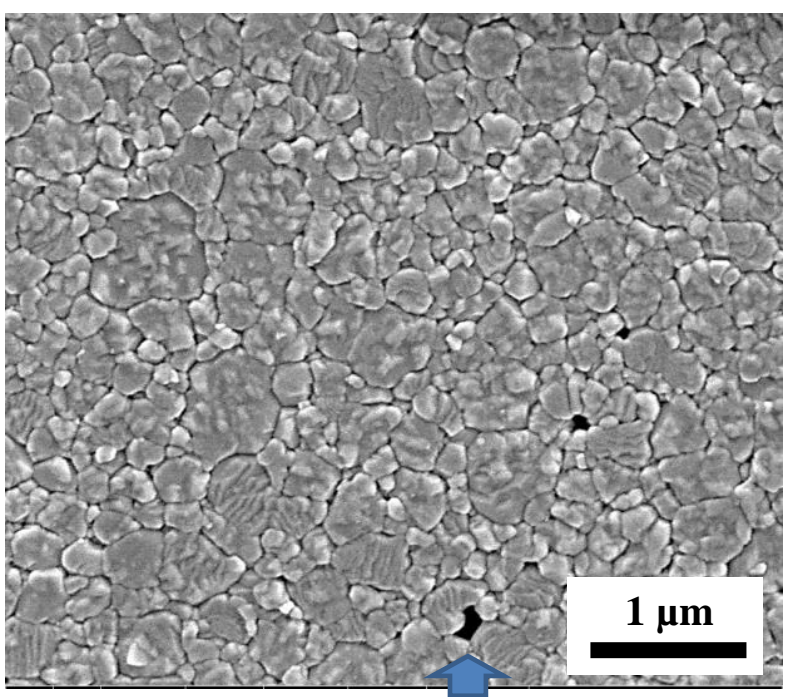

$50000 X$

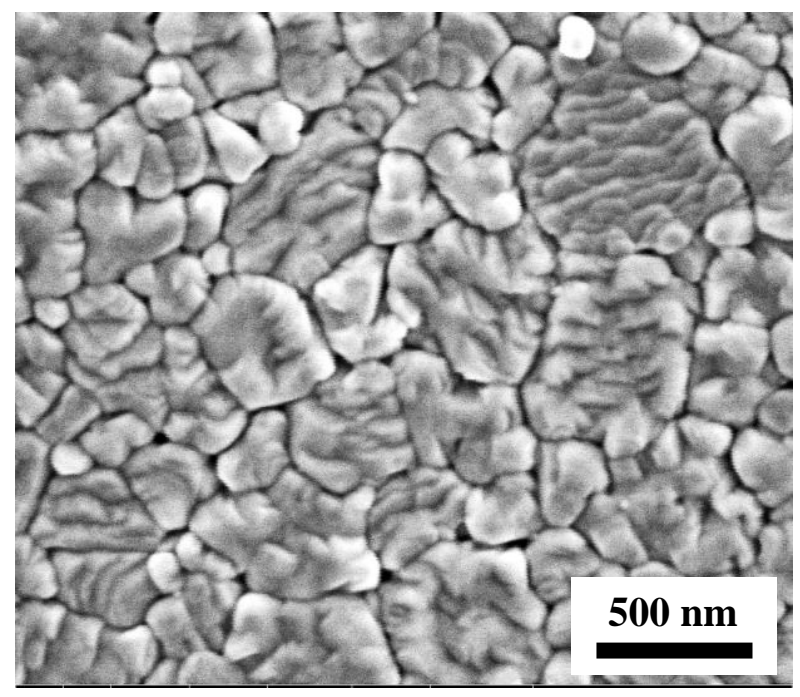

Figure 8 Experimental microstructure obtained for the optimized sintering cycle predicted by modeling.

\section{Conclusions}

A coupled sintering/grain growth model has been developed based on the continuum theory of sintering and applied to the optimization of sintering of zirconia powder used for dental implant applications. Constitutive equations have been derived for the modeling study and for the identification of the sintering and grain growth constitutive parameters. The sintering experiments performed under different temperatures reveal that the grain growth has two types of behaviors. The first behavior represents the slow grain growth for low temperatures, which can be possibly explained by the pore pinning of the grain boundaries, and the second behavior corresponds to the faster grain growth kinetics for temperatures higher than $1550{ }^{\circ} \mathrm{C}$. Both grain growth behaviors were identified using the experimental sintering data. The resulting sintering/grain growth model was used to predict the optimized sintering cycle which was too long to be completely explored experimentally (more than 10 hours). We determined through the two step sintering approach different sintering trajectories, and the optimal sintering cycle has been identified. The experimental verification of the optimal 
sintering cycle predicted by modeling rendered the average grain sizes close to the ones predicted by modeling and a high degree of densification. The experimentally observed localized porosity probably originated from the specimen cold pressing preparation.

\section{Acknowledgements}

The support of the NSF Division of Materials Research (Grant DMR-1900876) is gratefully acknowledged.

\section{References}

[1] L. Jiang, Y. Liao, Q. Wan, W. Li, Effects of sintering temperature and particle size on the translucency of zirconium dioxide dental ceramic, J. Mater. Sci. Mater. Med. 22 (2011) 2429-2435. doi:10.1007/s10856-011-4438-9.

[2] H.B. Zhang, B.-N. Kim, K. Morita, H. Yoshida, J.-H. Lim, K. Hiraga, Optimization of high-pressure sintering of transparent zirconia with nano-sized grains, J. Alloys Compd. 508 (2010) 196-199. doi:10.1016/j.jallcom.2010.08.045.

[3] M.-J. Kim, J.-S. Ahn, J.-H. Kim, H.-Y. Kim, W.-C. Kim, Effects of the sintering conditions of dental zirconia ceramics on the grain size and translucency, J. Adv. Prosthodont. 5 (2013) 161. doi:10.4047/jap.2013.5.2.161.

[4] C. Piconi, G. Maccauro, Zirconia as a ceramic biomaterial, Biomaterials. 20 (1999) 125. doi:10.1016/S0142-9612(98)00010-6.

[5] I. Denry, J. Kelly, State of the art of zirconia for dental applications, Dent. Mater. 24 (2008) 299-307. doi:10.1016/j.dental.2007.05.007.

[6] M.N. Rahaman, Sintering of Ceramics, CRC Press, 2007.

[7] R.M. German, Sintering Theory and Practice, Wiley, Wiley, 1996. http://www.wiley.com/WileyCDA/WileyTitle/productCd-047105786X.html.

[8] C. Manière, L. Durand, A. Weibel, C. Estournès, Spark-plasma-sintering and finite element method: From the identification of the sintering parameters of a submicronic $\alpha$ 
-alumina powder to the development of complex shapes, Acta Mater. 102 (2016) 169175. doi:10.1016/j.actamat.2015.09.003.

[9] E.A. Olevsky, Theory of sintering: from discrete to continuum, Mater. Sci. Eng. R Reports. 23 (1998) 41-100. doi:10.1016/S0927-796X(98)00009-6.

[10] R.K. Bordia, S.-J.L. Kang, E.A. Olevsky, Current understanding and future research directions at the onset of the next century of sintering science and technology, J. Am. Ceram. Soc. 100 (2017) 2314-2352. doi:10.1111/jace.14919.

[11] E.A. Olevsky, C. Garcia-Cardona, W.L. Bradbury, C.D. Haines, D.G. Martin, D. Kapoor, Fundamental Aspects of Spark Plasma Sintering: II. Finite Element Analysis of Scalability, J. Am. Ceram. Soc. 95 (2012) 2414-2422. doi:10.1111/j.15512916.2012.05096.x.

[12] E.A. Olevsky, D. V. Dudina, Field-Assisted Sintering, Springer International Publishing, Cham, 2018. doi:10.1007/978-3-319-76032-2.

[13] C. Manière, L. Durand, A. Weibel, C. Estournès, A predictive model to reflect the final stage of spark plasma sintering of submicronic $\alpha$-alumina, Ceram. Int. 42 (2016) 92749277. doi:10.1016/j.ceramint.2016.02.048.

[14] I.-W. Chen, X.-H. Wang, Sintering dense nanocrystalline ceramics without final-stage grain growth, Nature. 404 (2000) 168-171. doi:10.1038/35004548.

[15] V.V. Skorohod, Rheological basis of the theory of sintering, Nauk. Dumka, Kiev. (1972).

[16] J. Besson, M. Abouaf, Grain growth enhancement in alumina during hot isostatic pressing, Acta Metall. Mater. 39 (1991) 2225-2234. doi:10.1016/0956-7151(91)90004K.

[17] Z.-Z. Du, A.C.F. Cocks, Constitutive models for the sintering of ceramic components-I. Material models, Acta Metall. Mater. 40 (1992) 1969-1979. doi:10.1016/0956-7151(92)90183-F.

[18] L. Dejonghe, M. Rahaman, 4.1 Sintering of Ceramics, in: Handb. Adv. Ceram., Elsevier, 2003: pp. 187-264. doi:10.1016/B978-012654640-8/50006-7.

[19] F. Raether, P. Schulze Horn, Investigation of sintering mechanisms of alumina using kinetic field and master sintering diagrams, J. Eur. Ceram. Soc. 29 (2009) 2225-2234. 
doi:10.1016/j.jeurceramsoc.2009.01.025.

[20] J. Wang, R. Raj, Estimate of the Activation Energies for Boundary Diffusion from Rate-Controlled Sintering of Pure Alumina, and Alumina Doped with Zirconia or Titania, J. Am. Ceram. Soc. 73 (1990) 1172-1175. doi:10.1111/j.11512916.1990.tb05175.x.

[21] R.L. Coble, Sintering Crystalline Solids. I. Intermediate and Final State Diffusion Models, J. Appl. Phys. 32 (1961) 787-792. doi:10.1063/1.1736107.

[22] C. Herring, Effect of Change of Scale on Sintering Phenomena, J. Appl. Phys. 21 (1950) 301-303. doi:10.1063/1.1699658.

[23] M.I. Mendelson, Average Grain Size in Polycrystalline Ceramics, J. Am. Ceram. Soc. 52 (1969) 443-446. doi:10.1111/j.1151-2916.1969.tb11975.x. 


\section{Figure captions}

Figure 1 Experimental exploration of Zpex Smile zirconia pressure-less sintering, a) sintering cycles, b) grain size evolution in $1550^{\circ} \mathrm{C}$ tests, c) densification of the specimens obtained with 120 min dwell, d) average grain size of 120 min dwell specimens.

Figure 2 Identification of the densification behavior based on $5 \mathrm{~K} / \mathrm{min}$ sintering dilatometry (a) and experimental densification data modeled with and without grain growth (b).

Figure 3 Grain growth parameters identification at $1550{ }^{\circ} \mathrm{C}$.

Figure 4 Identification of the grain growth kinetics below $1550{ }^{\circ} \mathrm{C}$, a) modeled porosity evolution, b) modeled grain size evolution.

Figure 5 Identification of the grain growth kinetics above $1500{ }^{\circ} \mathrm{C}$, a) modeled porosity evolution, b) modeled grain size evolution.

Figure 6 Sigmoidal function used to model the grain growth behavior transition between 1500 and $1550{ }^{\circ} \mathrm{C}$.

Figure 7 Modeled sintering trajectories for the optimization of the sintering of the zirconia samples through the two step sintering approach, a) Temperature cycles, b) modeled porosity evolution, c) modeled grain size evolution, d) modeled sintering trajectories.

Figure 8 Experimental microstructure obtained for the optimized sintering cycle predicted by modeling. 